Original Article

\title{
Gum chewing while walking increases fat oxidation and energy expenditure
}

\author{
Susumu Kanno, MSc ${ }^{1)^{*}}$, Kanako Shimo, $\mathrm{MSc}^{1)}$, Tomonori Ando, MSc ${ }^{1)}$, \\ Yuka Hamada, PhD ${ }^{2,3)}$, Masashi Miyashita, $\mathrm{PhD}^{4}$, Kenji Osawa, $\mathrm{PhD}^{1)}$ \\ 1) LOTTE Co., Ltd. Central Laboratory: 1-1 Numakage 3-chome, Minami, Saitama 336-8601, Japan \\ 2) Graduate School of Sport Sciences, Waseda University, Japan \\ 3) Japan Society for the Promotion of Science, Japan \\ 4) Faculty of Sport Sciences, Waseda University, Japan
}

\begin{abstract}
Purpose] Although gum chewing while walking has been reported to increase walking speed and heart rate, its effect on energy expenditure remains unclear. The purpose of the present study was to investigate the effects of gum chewing while walking on fat oxidation, energy expenditure, and different walking parameters. [Participants and Methods] This randomized crossover study included 10 males and 5 females who walked for 15 min at their own pace while chewing 2 pieces of gum in the gum trial or while eating 2 tablets in the control trial. A wearable metabolic system, heart rate monitor, and pedometer measured fat oxidation, energy expenditure, heart rate, step count, and walking distance. Walking speed and stride length were also calculated. [Results] The energy expenditure, fat oxidation and heart rate were significantly higher during the gum trial than during the control trial. Significant increases were observed in the step count, walking distance, and walking speed but not in the stride length. [Conclusion] Our results suggest that gum chewing affects sympathetic nervous system activity and walking rhythm with a consequent improvement in the health-related effects of walking, which in turn helps to maintain weight. These findings may play a role in preventing the gradual age-related weight gain that predisposes to obesity.

Key words: Gum chewing while walking, Fat oxidation, Energy expenditure
\end{abstract}

(This article was submitted Dec. 19, 2018, and was accepted Feb. 1, 2019)

\section{INTRODUCTION}

The prevalence of obesity is increasing worldwide, so much so that it is being called a global pandemic ${ }^{1)}$. In Japan, the rate of obesity (defined as a $\mathrm{BMI} \geq 25 \mathrm{~kg} / \mathrm{m}^{2}$ ) was $31.3 \%$ among males and $20.6 \%$ among females in $2016^{2}$ ). These rates have not changed significantly in the last 10 years and are equivalent to tens of millions of people in Japan being obese. Obesity is associated with cardiovascular disease, metabolic disease, musculoskeletal disorders, cancer, and many other chronic diseases $^{3)}$. Effective methods of preventing and treating obesity are needed to influence the onset and progression of these associated diseases.

Chewing food slowly has long been regarded as healthy, and a Japanese study has in fact found a close relationship between eating quickly and obesity ${ }^{4}$. In an epidemiological study of adults (3,737 males and 1,005 females; mean age 48 years), eating speed correlated with obesity, and fast eaters had both a higher current BMI and greater increases in BMI from age 20 years. These differences remained statistically significant after correcting for other factors (energy intake, age, smoking, physical activity, and alcohol consumption). The Japanese Ministry of Health, Labour and Welfare has a program called "Kamingu 30" that recommends developing a habit of chewing every bite 30 times $^{5}$. However, surveys and assessments of the number of chews per bite in different populations have indicated that 30 chews per bite is not easy to achieve $e^{6-8)}$.

*Corresponding author. Susumu Kanno (E-mail: kanno_susumu@lotte.co.jp)

(C2019 The Society of Physical Therapy Science. Published by IPEC Inc.

(c) (1) $($ This is an open-access article distributed under the terms of the Creative Commons Attribution Non-Commercial No Derivatives

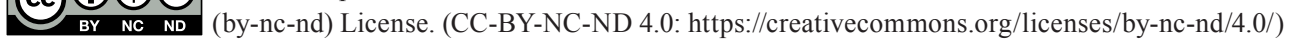


Chewing gum is a food that by its purpose and design is chewed numerous times ${ }^{9-12)}$. Gum chewing has been reported to increase sympathetic nervous system activity, heart rate, and energy expenditure ${ }^{13-18)}$. A "healthy women study" that compared a group that chewed gum for 15 minutes before oral glucose administration to a group that did not chew gum found that while blood glucose and insulin levels peaked after 30 minutes in both groups, the subsequent decline was significantly faster and larger in the gum group ${ }^{19}$. This suggests that mastication speeds up the insulin secretion response, which causes blood glucose levels to decline faster. Therefore, gum chewing may be an effective means of weight and glucose management.

Because exercise increases energy expenditure, gum chewing during exercise would be expected to result in higher energy expenditure than either exercise or gum chewing alone. Hence, combining exercise with gum chewing could be an effective method of weight management. We have previously evaluated the effects of gum chewing while walking on both physical functions such as walking distance, walking speed, step count, and stride length, and physiological functions such as heart rate and energy expenditure in a crossover trial ${ }^{20}$. We reported that the heart rate during walking was significantly higher when the participants chewed gum compared with the control arm when they did not chew gum. Stratified analyses by gender and age ( $\leq 39$ years $=$ young; $\geq 40$ years $=$ middle-aged and elderly) showed that walking distance, walking speed, step count, and energy expenditure were significantly higher among middle-aged and elderly males when walking while gum chewing compared to walking only. Thus, gum chewing while walking affects both physical and physiological functions. However, we calculated the increase in energy expenditure based on the increase in walking speed. Therefore, our results for the energy expenditure did not consider the effects of an increased heart rate as a function of the autonomic nervous system.

Therefore, in this study, we aimed to examine the effects of gum chewing on fat oxidation, energy expenditure, and walking indices in participants using a portable metabolic system while walking.

\section{PARTICIPANTS AND METHODS}

The participants were recruited among employees of the Lotte Central Laboratory via an electronic bulletin board that all employees can access via the company intranet. The inclusion criteria for study participants were being $\geq 20$ and $<60$ years old and in good health. Exclusion criteria were symptoms that could affect the ability to chew gum or walk, current treatment for a disease, and intake of supplements or health foods that promote energy or fat metabolism. The study was conducted with 16 participants who responded and met the inclusion criteria. One participant had to be excluded from the data analysis because of outlier measurements due to technical problems with data collection, leaving a total of 15 participants whose data could be analyzed (10 males, 5 females, age range $27-58$ years). Their mean age, height, weight, BMI, body fat percentage, and muscle mass were $35.4 \pm 9.9$ years, $166.4 \pm 8.3 \mathrm{~cm}, 62.3 \pm 10.5 \mathrm{~kg}, 22.6 \pm 4.0 \mathrm{~kg} / \mathrm{m}^{2}, 22.4 \pm 9.6 \%$, and $43.1 \pm 10.7 \mathrm{~kg}$, respectively [mean \pm standard deviation $(\mathrm{SD})]$.

This study was conducted with the approval of the ethics screening committee of Shiba Palace Clinic. It was also registered in advance with the University Hospital Medical Information Network Center (UMIN), a system for registering clinical trials (ID: UMIN000031404). After explaining the study to the participants orally and in writing, all participants provided their consent in writing.

This was a randomized crossover study with two study trials. Walking was selected as the mode of exercise for this study because it is the most widely used type of exercise in Japan ${ }^{21)}$. Before conducting the trials, all participants got accustomed to the device during a day of walking with the wearable metabolic system at the trial site.

Energy expenditure and walking parameters as described below were measured with participants walking at their own pace for 15 minutes on a 97-m track, once while chewing two pieces of gum ( $1.5 \mathrm{~g}$ per piece, gum trial) and another time while eating a tablet (control trial). The ingredients of the chewing gum were maltitol, sweetener (xylitol), flavoring (apple flavor), thickener (gum arabic), starch, and gum base. The tablet used in the control trial contained the same ingredients except for the gum base. The two trials were performed on different days in a random order. All trials were conducted at an ambient temperature set to $24^{\circ} \mathrm{C}$.

The primary outcome parameter of this study was fat oxidation. The secondary outcomes were energy expenditure, heart rate, walking distance, walking speed, step count, stride length. To measure energy expenditure, fat oxidation, and heart rate, the participants wore the main unit of the wearable K5 metabolic system (COSMED srl, Rome, Italy), which was connected to the face mask, on their back (device including battery weight $900 \mathrm{~g}$ ), and had the K5's heart rate monitor attached to their chest. The K5 system uses a galvanic fuel cell and a non-dispersive infrared sensor for the analysis of oxygen and carbon dioxide in the inhaled and exhaled air and an optoelectronic reader with a high performance turbine flowmeter to measure flow rate. The reader measures infrared light interruptions caused by the spinning blade inside the turbine. This study utilized a micro-dynamic mixing chamber measurement of gas exchange.

Walking distance was measured as the distance walked in 15 minutes on the 97-m track. The participants walked the track counterclockwise one by one at their own pace. Walking speed was calculated by dividing the total walking distance by the walking time of 15 minutes. Total step count was measured with a pedometer (Tanita ${ }^{\circledR}$ FB-731, Tanita Corp., Tokyo, Japan). Stride length was calculated by dividing the walking distance by the step count.

A p-value of $<0.05$ was considered to denote statistical significance. Statistical analysis was performed using IBM SPSS for Windows, version 20 (IBM Corp., Armonk, NY, USA). Data at rest and during the walking trial were compared using the paired t-test. 
Table 1. Physical and physiological data in the control and gum chewing trials

\begin{tabular}{lcc}
\hline & \multicolumn{2}{c}{$\mathrm{n}=15$ or 13} \\
\cline { 2 - 3 } & Control & \multicolumn{1}{c}{ Gum } \\
\hline Energy expenditure $(\mathrm{kcal} / \mathrm{min})$ & $4.0 \pm 0.2$ & $4.4 \pm 0.3^{*}$ \\
Fat oxidation $(\mathrm{kcal} / \mathrm{min})$ & $2.2 \pm 0.1$ & $2.5 \pm 0.2^{*}$ \\
Walking speed $(\mathrm{km} / \mathrm{h})$ & $4.9 \pm 0.2$ & $5.1 \pm 0.2^{*}$ \\
Steps $(\mathrm{steps} / 15 \mathrm{~min})$ & $1,759 \pm 32$ & $1,798 \pm 37^{*}$ \\
Stride $(\mathrm{cm} / \mathrm{step})$ & $69.6 \pm 1.4$ & $70.3 \pm 1.4$ \\
Heart rate $(\mathrm{bpm})$ & $96 \pm 4$ & $101 \pm 5^{*}$ \\
\hline
\end{tabular}

All values are given as the mean \pm SE. $* p<0.05$, control trial vs. gum trial. bpm: beats per minute. Heart rate data are presented for 13 participants.

\section{RESULTS}

There were no statistically significant differences between the gum chewing and the control trial prior to walking for resting heart rate ( $72 \pm 3 \mathrm{vs} .71 \pm 4 \mathrm{bpm}$ (mean \pm standard error $(\mathrm{SE}))$, energy expenditure $(1.4 \pm 0.1 \mathrm{vs} .1 .3 \pm 0.1 \mathrm{kcal} / \mathrm{min})$, and fat oxidation $(1.0 \pm 0.1$ vs. $0.8 \pm 0.1 \mathrm{kcal} / \mathrm{min}$, all $\mathrm{p}>0.05)$.

Energy expenditure during 15 minutes of walking was $4.4 \pm 0.3 \mathrm{kcal} / \mathrm{min}$ in the gum trial and $4.0 \pm 0.2 \mathrm{kcal} / \mathrm{min}$ in the control trial, representing a statistically significant $10.0 \%$ increase in the gum trial as compared to the control $(\mathrm{p}<0.05$, Table 1). Fat oxidation was $2.5 \pm 0.2 \mathrm{kcal} / \mathrm{min}$ in the gum trial and $2.2 \pm 0.1 \mathrm{kcal} / \mathrm{min}$ in the control trial, representing a statistically significant $13.6 \%$ increase in the gum trial as compared to the control $(\mathrm{p}<0.05$, Table 1$)$.

Walking speed during 15 minutes of walking was $5.1 \pm 0.2 \mathrm{~km} / \mathrm{h}$ in the gum trial and $4.9 \pm 0.2 \mathrm{~km} / \mathrm{h}$ in the control trial, which was a statistically significant difference $(\mathrm{p}<0.05$, Table 1$)$. The step count was $1,798 \pm 37 \mathrm{steps} / 15 \mathrm{~min}$ in the gum trial and $1,759 \pm 32 \mathrm{steps} / 15 \mathrm{~min}$ in the control trial, which was a statistically significant difference ( $<<0.05$, Table 1$)$. Stride length was $70.3 \pm 1.4 \mathrm{~cm} / \mathrm{step}$ in the gum trial and $69.6 \pm 1.4 \mathrm{~cm} / \mathrm{step}$ in the control trial, this difference was not significant (Table 1).

Heart rate could not be accurately measured in two of the 15 participants, resulting in data for 13 participants being analyzed. Heart rate during 15 minutes of walking was $101 \pm 5 \mathrm{bpm}$ in the gum trial and $96 \pm 4 \mathrm{bpm}$ in the control trial. The heart rate in the gum trial was therewith significantly higher $(\mathrm{p}<0.05$, Table 1$)$.

\section{DISCUSSION}

In this study, fat oxidation increased significantly in healthy adult males and females when walking while gum chewing compared with while eating a tablet. Further, gum chewing while walking was associated with increased heart rate and energy expenditure.

The obesity rates of Japanese males and females in their 20 s were $25.7 \%$ and $9.5 \%$, respectively, in the 2016 National Health and Nutrition Survey ${ }^{2}$. These percentages increase with age, peaking for males in their 50s and females in their $60 \mathrm{~s}$ at $36.5 \%$ and $24.2 \%$, respectively. For an average-weight male (height $171.5 \mathrm{~cm}$, weight $67.6 \mathrm{~kg}$ ) in his $20 \mathrm{~s}$ to reach a BMI of $25 \mathrm{~kg} / \mathrm{m}^{2}$ after 10,20 , or 30 years, he would have to gain on average $0.6 \mathrm{~kg} /$ year, $0.3 \mathrm{~kg} /$ year, and $0.2 \mathrm{~kg} /$ year, respectively. The same survey found that males and females in their 30 s walked 7,257 steps per day on average. Based on the step count achieved during 15 minutes of walking in the control trial in our study, this means males and females in their 30s walk for 61.9 minutes each day. Energy expenditure was increased by $0.4 \mathrm{kcal} / \mathrm{min}$ in the gum trial in our study. Assuming gum was chewed every time when walking throughout the day, energy expenditure could increase by $24.8 \mathrm{kcal} /$ day. If done every day, this would increase energy expenditure by $9,052 \mathrm{kcal} / \mathrm{year}$, or, if only half the time was spent walking, by $4,526 \mathrm{kcal} / \mathrm{year}$. Given that the energy cost of $1 \mathrm{~kg}$ of body weight is about 7,000 kcal, gum chewing while walking about 61.9 min per day could prevent a weight gain of $1.3 \mathrm{~kg} /$ year, or of $0.6 \mathrm{~kg} /$ year if walking half the time. While the energy of the gum itself need to be considered, these results indicate that gum chewing while walking could help maintain weight and prevent the observed weight gain with age leading to obesity in Japanese males.

Gum chewing at rest has been reported to increase sympathetic nervous system activity, heart rate, and energy expenditure ${ }^{13,15)}$. Oxygen uptake can be estimated from individual walking speed, and this can be used together with a person's body weight to calculate energy expenditure (American College of Sports Medicine) as follows:

Estimated oxygen uptake $(\mathrm{mL} / \mathrm{kg} / \mathrm{min})=3.5(\mathrm{~mL} / \mathrm{kg} / \mathrm{min})+0.1(\mathrm{~mL} / \mathrm{kg} / \mathrm{m}) \times$ walking speed $(\mathrm{m} / \mathrm{min})$

Energy expenditure $(\mathrm{kcal} / \mathrm{min})=$ estimated oxygen uptake $(\mathrm{L} / \mathrm{min}) \times 4.9(\mathrm{kcal})$

With this formula, energy expenditure during the gum trial vs. the control trial would have been $3.64 \pm 0.16 \mathrm{kcal} / \mathrm{min}$ vs. $3.55 \pm 0.15 \mathrm{kcal} / \mathrm{min}$, respectively, which are lower values than the measurements obtained with the metabolic system. Energy expenditure based on estimated oxygen uptake would only be $2.5 \%$ higher in the gum as compared to the control 
trial, whereas it was $10.0 \%$ higher when measured with the metabolic system. While a definite conclusion cannot be drawn due to the differences in the calculation methods, it appears highly likely that factors other than walking speed had an impact on the results. In previous measurements at rest, energy expenditure increased by $19 \pm 4 \%$ from baseline among seven non-obese participants chewing $8.4 \mathrm{~g}$ of gum at a pace of $100 \mathrm{times} / \mathrm{min}$, which indicates that gum chewing has considerable thermogenic activity ${ }^{15)}$. The increase when standing was $11 \pm 11 \%$. An assessment of autonomic nervous system activity at rest found that when 11 healthy males chewed two pieces of gum $(6.18 \mathrm{~g})$ at a pace of 60 times/min, sympathetic nervous system activity, heart rate, and plasma catecholamine levels increased, and peripheral blood vessels contracted ${ }^{14)}$. The authors attributed this to a different regulatory mechanism from what is seen during full-body exercise. Taken together, these results suggest that gum chewing while walking increases sympathetic nervous system activity, and may further increase fat oxidation and energy expenditure.

Gum chewing in our study significantly increased walking speed and step count, but no effect on stride length was found. A possible explanation could be the phenomenon of cardiac-locomotor synchronization (CLS), or cardiac-locomotor coupling, which is when locomotor activity rhythms synchronize with heart rhythm ${ }^{22}$. The increased heart rate caused by gum chewing could have produced CLS, which then impacted physical function to result in increased walking distance, walking speed, and step count. It has further been reported that the tempo of background music affects the tempo of exercise ${ }^{23,24)}$. While the number of times gum was chewed during a defined amount of time was not measured in our study, mastication is a kind of motor rhythm. Therefore, the tempo of gum chewing could have affected the walking tempo in our study, thereby increasing walking speed. While we previously established that gum chewing increased walking speed in middle-aged and elderly males ${ }^{20)}$, the present study demonstrated this increase also in younger males and females. Our previous study did not observe an increase in the heart rate in young participants ${ }^{20)}$; therefore, failure of CLS to occur in the young group could be an explanation why walking speed was not increased. In a study of males and females in their $20 \mathrm{~s}(22.6 \pm 1.9$ years), the gum chewing speed at rest was $87.1 \pm 1.0$ times $/$ min. Considering $95.4 \%$ of all measurements (mean $\pm 2 \mathrm{SD}$ ), the range was 65-109 times/min ${ }^{12}$. Previous research has shown less masticatory muscle activity in females as compared with males, and, while the results in males were not affected by age, middle-aged and elderly females exhibited less masticatory muscle activity than young females ${ }^{25}$. These studies found an increase in the heart rate among middle-aged and elderly females when gum chewing while walking, but not in walking speed. This could have been partially the result of a lower chewing frequency due to reduced masseter muscle activity. The above findings suggest that age, gender, and individual differences in how gum chewing affects walking speed and heart rate during walking could have impacted the results of our study. This requires further investigation.

This was the first study to use a wearable metabolic system to measure the effects of gum chewing on fat oxidation and energy expenditure while also analyzing different walking parameters. The small number of participants with only five females and the wide age range are considered limitations of our study that made it impossible to conduct age- or genderspecific analyses.

It would be interesting to measure masticatory capacity at rest and while walking, and investigate the effects of gum chewing on physical and physiological functions in larger study populations with different age groups and equal representation of both genders.

In conclusion, the present study found that gum chewing while walking impacted fat oxidation and energy expenditure. These effects appear to result from increased sympathetic nervous system activity and higher intensity of exercise. Thus, gum chewing while walking may help maintain weight and play a role in preventing the gradual age-related weight gain leading to obesity in the population.

\section{Presentation at a conference}

Our research presented in the 73th Japanese Society of Physical Fitness and Sports Medicine (2018).

\section{Funding and Conflict of Interest} Ltd.

In the related research, M. Miyashita received research grants and Y. Hamada received traveling expenses from Lotte Co.,

\section{REFERENCES}

1) Swinburn BA, Sacks G, Hall KD, et al.: The global obesity pandemic: shaped by global drivers and local environments. Lancet, 2011, 378: 804-814. [Medline] [CrossRef]

2) Ministry of Health, Labour and Welfare: The National Health and Nutrition Survey in Japan, 2016. (in Japanese). https://www.mhlw.go.jp/bunya/kenkou/ eiyou/d1/h28-houkoku.pdf (Accessed Oct. 31, 2018)

3) World Health Organization: Global health observatory, obesity, situation and trends. Geneva: World Health Organization, updated October 2017. http://www. who.int/mediacentre/factsheets/fs311/en/ (Accessed Oct. 31, 2018)

4) Otsuka R, Tamakoshi K, Yatsuya H, et al.: Eating fast leads to obesity: findings based on self-administered questionnaires among middle-aged Japanese men and women. J Epidemiol, 2006, 16: 117-124. [Medline] [CrossRef]

5) Ministry of Health, Labour and Welfare: Study group report on dental health and dietary education (in Japanese). https://www.mhlw.go.jp/shingi/2009/07/d1/ 
s0713-10a.pdf (Accessed Oct. 31, 2018)

6) Japan Society of School Health: Investigation committee report on actual conditions of food and chewing. 2010, pp 1-97. Japan Society of School Health (in Japanese).

7) Nakamura T, Hosoya N: Study on eating behavior and physical activities in overweight subjects. Jpn J Nutr, 1986, 44: 69-78 (in Japanese). [CrossRef].

8) Kobayashi C, Fukushima S, Taguchi Y, et al.: An experimental study on mastication using restored school lunches with three different types of food. Jpn J Ped Dent, 2005, 43: 389-399 (in Japanese).

9) Nakagawa H, Hatae K, Matai N, et al.: Evaluation of food texture by measuring masticatory movements. J Home Econ Jpn, 1991, 42: 347-354 (in Japanese).

10) Tamura A, Yanagisawa Y, Teramoto Y, et al.: A study on the physical properties of food and ingestion functions. The 2 nd report: an electromyographic study of foods in relation to their physical properties. Jpn J Ped Dent, 1985, 23: 962-983 (in Japanese).

11) Michiwaki Y, Kinumatsu Y, Yokoyama M, et al.: Influence of sizes and textures of foods on mandibular movement during mastication. J Jpn Stomatol Soc, 2001, 50: 70-75 (in Japanese).

12) Sakanoshita N, Ozaki F, Oosawa K, et al.: Number of chews and mastication frequency of gum chewing. J Jpn Soc Mastication Sci Health Promot, 2017, 27: 10-17 (in Japanese).

13) Suzuki M, Shibata M and Sato Y.: Energy metabolism and endocrine responses to gum-chewing. Journal of Japanese Society for Mastication Science and Health Promotion, 1992, 2: 55-62 (in Japanese).

14) Ishiyama I, Suzuki M, Matsubara S, et al.: Function of sympathetic and parasympathetic nerves during gum chewing with CVRR, wave height of plethysmogram and plasma catecholamine concentration as functional indices of autonomic nerves. Journal of Japanese Society for Mastication Science and Health Promotion, 1998, 8: 42-52 (in Japanese).

15) Levine J, Baukol P, Pavlidis I: The energy expended in chewing gum. N Engl J Med, 1999, 341: 2100. [Medline] [CrossRef]

16) Farella M, Bakke M, Michelotti A, et al.: Cardiovascular responses in humans to experimental chewing of gums of different consistencies. Arch Oral Biol, 1999, 44: 835-842. [Medline] [CrossRef]

17) Hasegawa Y, Sakagami J, Ono T, et al.: Circulatory response and autonomic nervous activity during gum chewing. Eur J Oral Sci, 2009, 117: 470-473. [Medline] [CrossRef]

18) Kresge DL, Melanson K: Chewing gum increases energy expenditure before and after controlled breakfasts. Appl Physiol Nutr Metab, 2015 , 40: 401-406. [Medline] [CrossRef]

19) Hashimoto K, Matsuda H, Takada K, et al.: Study of the relation between mastication and insulin secretion. Gum base mastication. Journal of Japanese Society for Mastication Science and Health Promotion, 2004, 14: 23-28 (in Japanese).

20) Hamada Y, Yanaoka T, Kashiwabara K, et al.: The effects of gum chewing while walking on physical and physiological functions. J Phys Ther Sci, 2018, 30: 625-629. [Medline] [CrossRef]

21) Ministry of Education, Culture, Sports, Science and Technology (MEXT): Public opinion survey on physical fitness and sports (survey in January 2013). http:// www.mext.go.jp/component/b_menu/other/_icsFiles/afieldfile/2013/08/23/1338732_1.pdf(Accessed Oct. 31, 2018)

22) Takeuchi S, Nishida Y: Possible application of cardiac-locomotor synchronization in physical therapy. Rigakuryoho Kagaku, 2009, 24: 777-784 (in Japanese).

23) Edworthy J, Waring H: The effects of music tempo and loudness level on treadmill exercise. Ergonomics, 2006, 49: 1597-1610. [Medline] [CrossRef]

24) Powell W, Stevens B, Hand S, et al.: Sounding better: fast audio cues increase walk speed in treadmill-mediated virtual rehabilitation environments. Stud Health Technol Inform, 2010, 154: 202-207. [Medline]

25) Furuya M, Yoshida M, Nokubi T, et al.: Evaluation of masticatory function by using the testing gumi-jelly—influence of age and sex on dentate subjects. Jpn Prosthodontic Soc, 1994, 38: 89-97 (in Japanese). [CrossRef] 